\section{SOUTHERN TRANSVAAL BRANCH}

\section{Recent Lectures}

Miss Savin's lecture on Geriatrics was followed up by a tour of the Old Aged Home in Sandringham.

In conjunction with the General Meeting in March, Mr. Neville Cohen, a paraplegic, gave a talk about some of his experiences since his injury. As these included driving his hand-controlled car to England and back again, it proved quite an eye-opener to us. It was also a great stimulus to the three paraplegic patients who were invited from the wards. It would be interesting to hear the impressions of other long term patients regarding hospital life.

Miss Winter gave a stimulating lecture on a controversial subject viz. "Manipulations in the Treatment of Disc Lesions," which left the audience with much food for thought.

\section{Future Lectures}

On May 17th, Miss Jean Blair will talk about her trip to the Physiotherapy Congress in Paris, and all of us who know her are looking forward to this.

The Northern Transvaal Branch secretary, Miss Savin, has extended a very friendly invitation on behalf of her committee for our branch members to attend any of the Society lectures held in Pretoria. Unfortunately we cannot circularize all members about each lecture, but details may be obtained from Miss Schwartz.

We have issued a circular invitation to Northern Transvaal members and we look forward to seeing them at our lectures.

\section{Marriages}

Miss Delyse Dunsden to John Hart in Benoni.

Miss Valery Schwartz to Dr. Rudolph in Johannesburg. Miss J. Pilling, on 5/12/59 to Mr. Reg Van Dyk.

Miss E. Edelinghuys, on 2/4/59 to Dr. Hans Opperman.

\section{Births}

To Mrs. B. H. de Bruin (neé Klooster) on Monday, April 18th, a son, Andries Willem Johannes.

To Mrs. N. van Heerden, on Tuesday, March 17th, a daughter, "Alta."

To Mrs. R. M. Jubson, on Saturday, A pril 23rd, a son.

\section{IN MEMORIUM. \\ MRS. BRONWEN FOURIE, M.C.S.P.}

Trained: at St. Thomas' Hospital, London.

Joined: S.A.S.P., Northern Transvaal Branch, 1952.

I have known Bronnie Fourie (born Vaughan) for the past seven years. She had been away in America for four years, where her husband Brand Fourie, was on the South African ambassadorial staff. As soon as she returned to South Africa she took up her profession as Physiotherapist, and I was indeed most fortunate to obtain her services in charge of my department.

Bronnie Fourie was a born Physiotherapist, for she had the outstanding qualities of humanity, in that she treated all patients, rich and poor white or coloured according to their needs, and with the utmost sympathy and understanding. She was most capable, and even tempered and above all had a sense of humour. She enjoyed her work.

She left South Africa with her husband on his appointment as South African representative to the United Nations, and her only regret on leaving, was that she would not be able to carry on her work as Physiotherapist.

After a year at the United Nations headquarters she returned to South Africa on a short visit to her parents, and it was then she met her tragic end in a motor accident.

The Society of Physiotherapists was deprived of one of its ablest members.

We extend our sincere sympathy to her husband, her parents and the rest of the family, in their untimely and sad bereavement.

H. D. EPSTEIN,
QUESTIONS FOR JOURNAL QUESTION BOX.

1. When is it safe to give movements of nearby joints following a Skin Graft ?

2. Is it true, that cases of Disseminated Sclerosis are rarely found in South Africa, and only in people who have already developed it overseas?

3 . Is it really necessary to remove clothing, when applying SHORT-WA VE Diathermy? Many Physiotherapists in this country disregard this precaution, stating that they have never burnt a patient.

4. What type of Physiotherapy has been found to be most effective in treating hand injuries.

5. Should the grading of muscle power be standardised throughout South Africa.

These questions will be answered by Specialists in each field but in the meantime members are invited to send in their own ideas and suggestions for discussion.

\section{BOOK REVIEW}

\section{Practical Electrotherapy for Physiotherapists By Brenda Savage.}

Published by: Faber \& Faber, 24 Russel Square, London, W.C.I.

$$
\text { Price 30/- net. }
$$

This book gives a short introductory chapter on some physical and mechanical principles of various current forms and pieces of electrical apparatus. In this chapter it also deals with the role played by the skin in the application of different electrical treatments.

It deals further with the physiological effects on the body produced by different forms of electrical and radiation treatments. It also describes in detail the technique of some basic forms of treatments by Electrotherapy, i.e. the applications of Direct Current, certain ionisation treatments as Histamine and Renotin ionisation, the distribution of electrical fields in High Frequency current treatments, the application of S.W.D. coils, and the technique of giving General and Local U.V.R.

And finally and mainly it deals with a vast number of conditions that can be treated by means of Electrotherapy. In this part of the book different forms of treatment are discussed, some of the more specialised ones being described in detail.

The book is illustrated by a great number of very clear and valuable diagrams.

This book is a must in any Physiotherapy library. It is one of very few books attempting to give a detailed account on techniques and possibilities in Electrotherapy, something sadly lacking up to now as contrasted with the vast number of books being written and published on the electrical and mechanical part of Electrotherapy apparatus.

We are sure that every physiotherapist and physiotherapy student will be very grateful indeed to be able to acquire a book that deals with the practical application of treatments by Electrotherapy.

\section{BALANCE (Continued from Page 7).}

abovementioned cases vitamin therapy combined with intensive physiotherapy will lead to a cure in most of them. The results in tabes dorsalis are unfortunately less encouraging, because damage to the nervous system is usually irreversible. Nevertheless graduated exercises with special attention to the development of other sensory mechanisms, especially the eyesight, very often have very gratifying results.

I believe special physiotherapeutic methods have been devised in the treatment of vestibular disturbances. Of these I have no experience.

The ultimate outcome in cerebellar ataxia is that of a bed-ridden patient, but physiotherapy can postpone this considerably and give the patient many years of useful life. 